\title{
The Effects of Nanosilica on Charpy Impact Behavior of Glass/Epoxy Fiber Reinforced Composite Laminates
}

\author{
Ömer Yavuz Bozkurt ${ }^{1}$, Özkan Özbek ${ }^{1}$, Atban Rafea Abdo ${ }^{2}$ \\ ${ }^{1}$ Mechanical Engineering Department,Gaziantep University, Gaziantep, Turkey \\ ${ }^{2}$ Ministry of Industry and Minerals, The State Company for Textile Industries and Leather Cotton Factory, Anbar, Iraq
}

\begin{tabular}{l}
\hline Article Info \\
\hline Article history: \\
Received May $30^{\text {th }}, 2017$ \\
Revised Aug $20^{\text {th }}, 2017$ \\
Accepted Oct $18^{\text {th }}, 2017$ \\
\hline
\end{tabular}

\section{Keyword:}

Charpy impact

Glass fiber

Nanosilica

\begin{abstract}
Desire to improve the efficiency of composite materials for engineering applications has led to the use of nano-sized additives or fillers such as nanoclay, nanosilica, nano-graphene, carbon nanotubes. The effect of nanoparticle inclusion on mechanical properties of fiber reinforced composite materials has been investigated by many researchers and crucial effects have been reported in several papers. In this work, the effects of nanosilica content on the low velocity impact behaviors of glass/epoxy fiber reinforced composite laminates are determined using Charpy impact tests. The composite laminates are fabricated via hand lay-up followed by hot press molding. The nanosilica particles with different weight percentages are dispersed in epoxy resins using mechanical stirring. The absorbed impact energy values of flatwise-unnotched and edgewise-notched beam specimens, and impact damages are analyzed as a measure of impact behavior. The results show that the incorporation of nanosilica particles have significant effects on the Charpy impact behavior.
\end{abstract}

\section{Corresponding Author:}

Özkan Özbek,

Mechanical Engineering Department,

Gaziantep University,

27310, Gaziantep, Turkey.

Email: ozkanozbek@gantep.edu.tr

\section{Introduction}

In the past few decades, fiber reinforced composite materials have become promising materials in aerospace, automotive, marine and defense industries due to their outstanding performance-to-weight ratio, better damping characteristics, good fatigue resistance, high resistance to corrosion when compared to conventional engineering materials. However, they have low intensity on the impact behavior because its brittle characteristics. Heavier design, so reduction in strength of the materials, may be necessary to satisfy requirement of the system safety. One of the techniques to improve the impact damage resistance of fiber reinforced polymer composites are the addition of small amounts of nanoparticles into the matrix of composites.

Desire to improve the efficiency of composite materials for engineering applications, has led to the use of nano-sized additives or fillers such as nanoclay, nanosilica, nano-graphene, carbon nanotubes. The effect of nanoparticle inclusion on mechanical properties of fiber reinforced composite materials has been investigated by many researchers and crucial effects have been reported in several papers [1]. Nano silica particle is the one of the common nanoparticles used in literature studies to improve behaviors of fiber reinforced composite materials. Due to better mechanical properties, nanosilica inclusion in polymer composite has been used in many areas such as automotive, electronics, aerospace industries [2-3].

Several studies related to nanosilica incorporation on polymer based composite materials are present in the literature. Kuzmin et al. [4] conducted a study related to surface modification of basalt fibers by coating the 
fibers with nanosilica particles. $23 \%$ increase in tensile strength was obtained from the sample having 0.1 wt.\%nanosilica inclusion when compared to non-coated fibers. Different weight percentages of nano silica particles were considered as between the $0.1 \mathrm{wt} . \%$ and $1 \mathrm{wt} . \%$. Huang and Tsai [5] researched the effect of nanosilica and rubber particles on the vibration and damping behavior of E-glass fiber reinforced composite laminates. The samples having different stacking sequences and nanoparticle incorporation in epoxy component were prepared and the obtained results were compared with the pure ones. Zeng et al. [6] examined the fracture toughness characteristics of carbon fibre/epoxy laminates by adding the nanosilica and rubber particles. The highest improvement comparing to sample without nanoparticle was obtained from 10 wt. \% rubber addition as 2.5 times. Nanosilica incorporation showed the 20-30\% increase in fracture toughness. Manjunatha et al. [7] investigated the tensile fatigue behavior of glass fibre reinforced epoxy composites having $10 \mathrm{wt}$. \%nanosilica particles. Fatigue life of samples having nanosilica was improved with three or four times compared to pure samples. Kang et al. [8] derived an advanced proof material for body armor materials. Kevlar fiber reinforced composites were prepared with incorporation of the fumed silica. Kevlar/silica composite fabric exposed to quasi-static stab testing and impact tests. The samples having silica particles showed the better results than pure ones. Rosso et al. [9] employed the well-dispersed silica nanocomposites for tensile and fracture tests. The author indicated that the addition of ratio of 5\% silica nanoparticles from the total volume of composite material could be developed the stiffness and facture energy at the range from $20 \%$ to $140 \%$. Zamanian et al. [10] noticed that the mechanical characteristics of an epoxy resin have been improved drastically by the addition of silica nanoparticles with various sizes, the best improvements being approached with the smaller nanoparticles.

In this work, the effects of nanosilica content on the low velocity impact behaviors of glass/epoxy fiber reinforced composite laminates are determined using Charpy impact tests. The nanosilica particles with different weight percentages are dispersed in epoxy. Absorbed impact energy values of beam specimens, and impact toughness are analyzed as a measure of impact behavior.

\section{Materials \& Methods}

Plain weave E-glass fabrics having $202 \mathrm{~g} / \mathrm{m}^{2}$ areal density, epoxy resin (MOMENTIVE-MGS L285) and hardener (MOMENTIVE-MGS H285) were purchased from DOST Chemical Industrial Raw Materials Industry, Turkey. Nanosilica particles having average particular dimension, specific surface area, mass density and high purity as $15 \mathrm{~nm}, 300 \mathrm{~m}^{2} / \mathrm{g}, 0.05 \mathrm{~g} / \mathrm{cm}^{3}, 99.5 \%$, respectively, were supplied by Grafen Chemical Industries, Turkey. Firstly, epoxy resin/nanosilica mixtures were prepared in a beaker according to different weight percentages of nanosilica particles as $0.5,1.0,1.5,2.0$ and 3.0. The mixture were blended by mechanical stirring to provide homogeneous mixture. Then, hardener was added to mixture in the weight ratio of mixture/hardener as 100:40 and stirred again.

Step by step representation of fabrication procedure are given in Fig. 1a. Hand layup technique, shown in Fig. $1 \mathrm{~b}$, was conducted to obtain composite laminates. For this purpose, a thin release agent and a layer of glass fabric were placed on the below mold plate. Then, resin mixture was applied on the fabric layer with a help of brush. Afterwards, second fabric layer was placed and resin mixture was applied, respectively. This process was repeated until twelve layers were stacked. Lastly, top mold plate was deposited on the wet fabric layers. After finishing the preparation of combination of resin mixture and fabric layers, curing process was performed as shown in Fig. 1c in a hot press. Charpy impact test specimens were cut on the mini CNC machine. All this procedure was applied for each nanosilica content. 

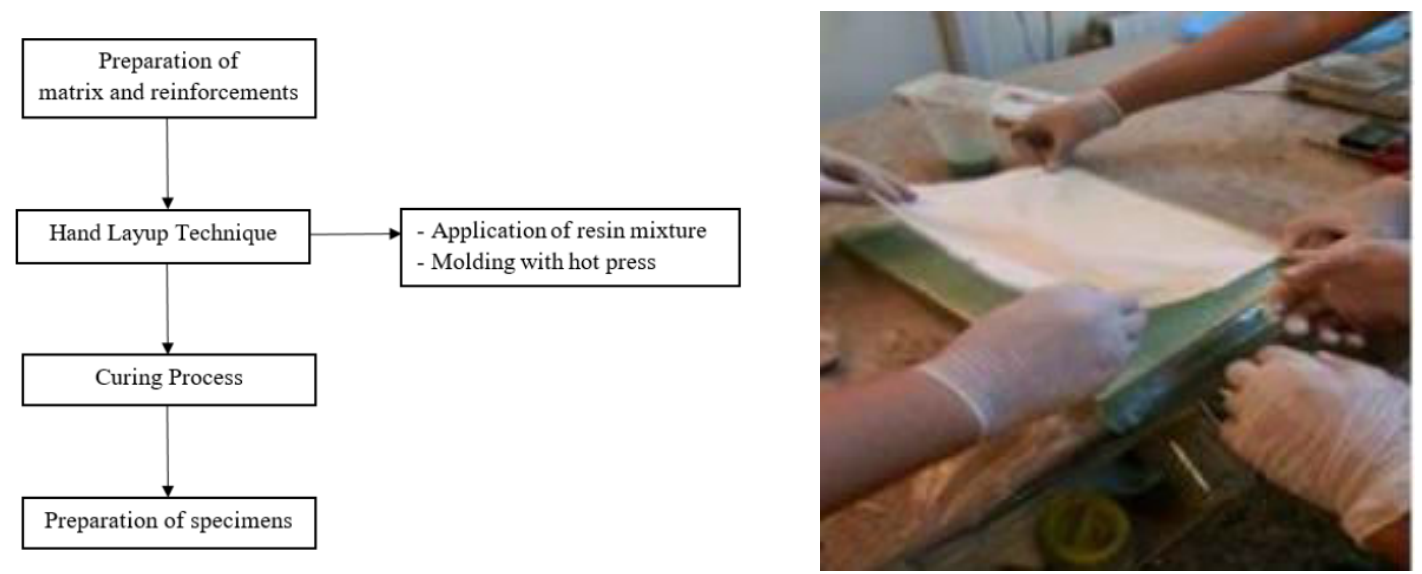

a) b)

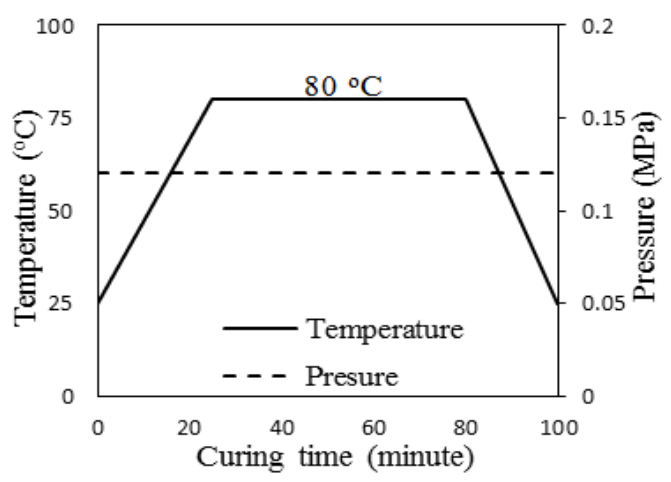

c)

Figure 1. Fabrication Process; a) step by step representation of fabrication, b) hand layup technique, c) curing process.

Charpy impact tests were conducted by Köger 3/70 Charpy impact test machine, which is shown in Fig. 2 and Fig.3, for determining the impact behavior of composite laminates having nanosilica particles. The specimens with dimensions of $55 \mathrm{~mm}$ x $10 \mathrm{~mm}$ were prepared in accordance with ISO 179/92 standard [12]. Notched and unnotched specimens were exposed to edgewise and flatwise impact loading, respectively. Five specimens were tested for each configuration. All experiments carried out at standard room temperature.

Absorbed impact energy and impact toughness for each specimen are determined by following equation (1) and (2);

$$
E=E_{a}-E_{b}
$$

$$
a_{c u}=E /(b h)
$$

where, $\mathrm{E}, \mathrm{E}_{\mathrm{a}}, \mathrm{E}_{\mathrm{b}}, \mathrm{a}_{\mathrm{cu}}, \mathrm{b}$ and $\mathrm{h}$ represents the absorbed impact energy, potential energy of the weighted pendulum before and after impact, impact toughness, width and thickness of the specimen. 


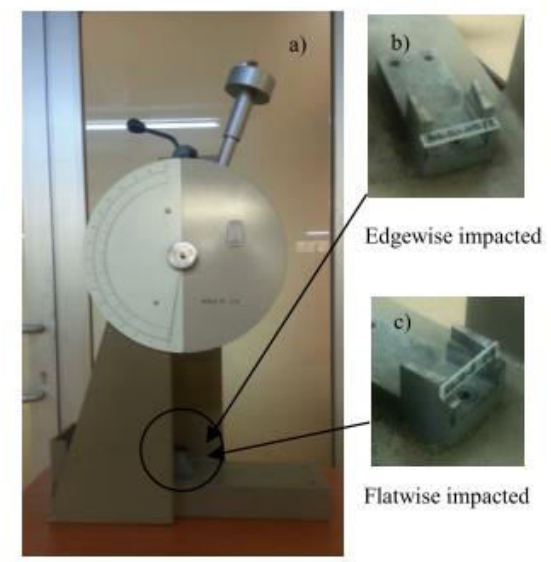

Figure 2. Köger 3/70 Charpy impact tester; a) the calibrated dial on the impact tester, b) edgewise impacted notched test specimen, c) flatwise impacted unnotched test specimen.

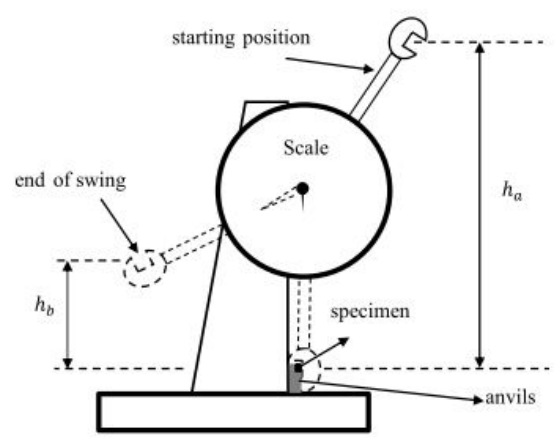

Figure 3. Schematic illustration of Charpy impact test.

\section{Results \& Discussions}

The Charpy impact test was performed to observe effects of nanosilica inclusion of the impact behavior of glass/epoxy fiber reinforced composite laminates.

The impact energy and impact toughness values for edgewise (notched) were plotted versus nanosilica contents in Fig. 4 and Fig. 5. GFRE means the pure epoxy laminates that has no addition of silica particles in all figures. For the edgewise specimens, the maximum impact energy and toughness values are obtained from the specimen having $1.5 \%$ nanosilica inclusion as $3.34 \mathrm{~J}$ and $156.84 \mathrm{~kJ} / \mathrm{m}^{2}$. All silica particles inclusions have the increase comparing to pure one. The results for impact energy and toughness give an idea that there is an improvement trend up to $1.5 \%$ and afterwards decreasing trend happens. This can be related to some agglomerations resulted with a weak interfacial adhesion between the matrix and nanoparticles.

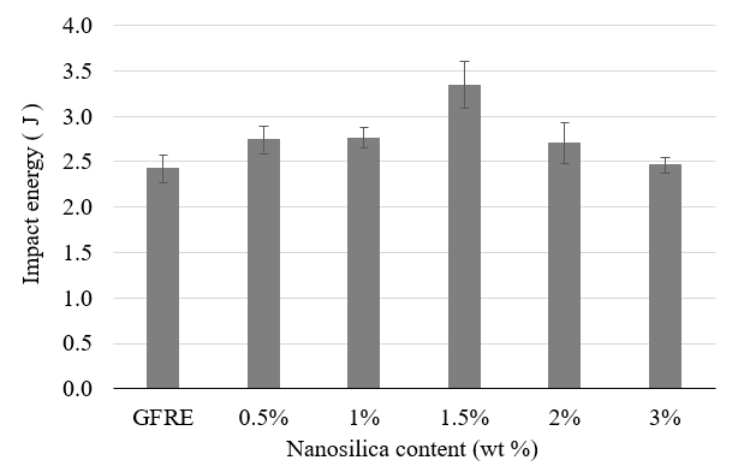

Figure 4. Impact energy of edgewise-notched impacted with respect to nanosilica content. 


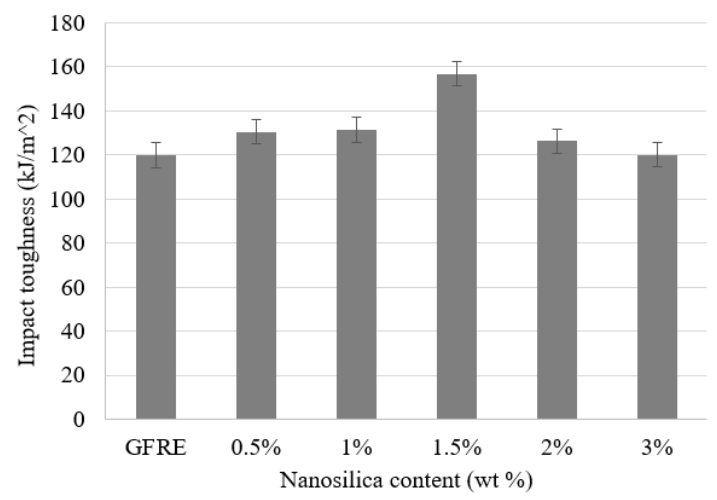

Figure 5. Impact toughness of edgewise-notched impacted with respect to nanosilica content.

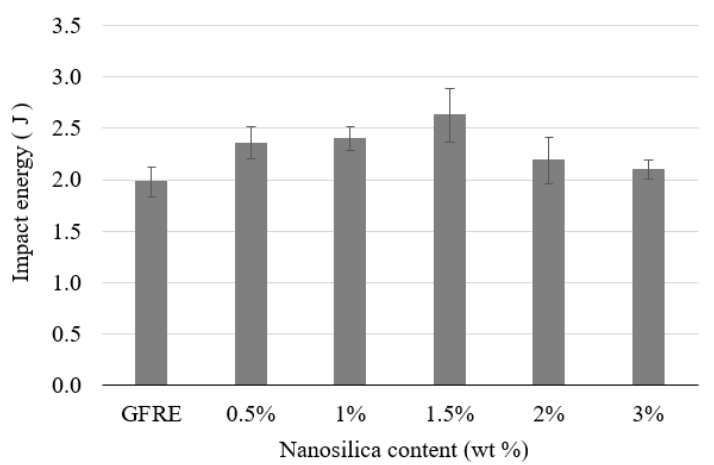

Figure 6. Impact energy of flatwise-unnotched impacted with respect to nanosilica content.

The Figures 6 and 7 are represent the impact energy and toughness results that belong the flatwise (unnotched) specimens. For the results belong the flatwise specimens, they have similar fashion with the edgewise results. The best improvement are obtained from the $1.5 \%$ nanosilica incorporation again as $2.63 \mathrm{~J}$ and $124.67 \mathrm{~kJ} / \mathrm{m}^{2}$. At this point, $32.8 \%$ and $27.1 \%$ increase in impact energy and toughness are ensured against to pure ones. In the literature, several similar results were reported for the decreasing trend after a certain value of nanoparticle inclusion [11].

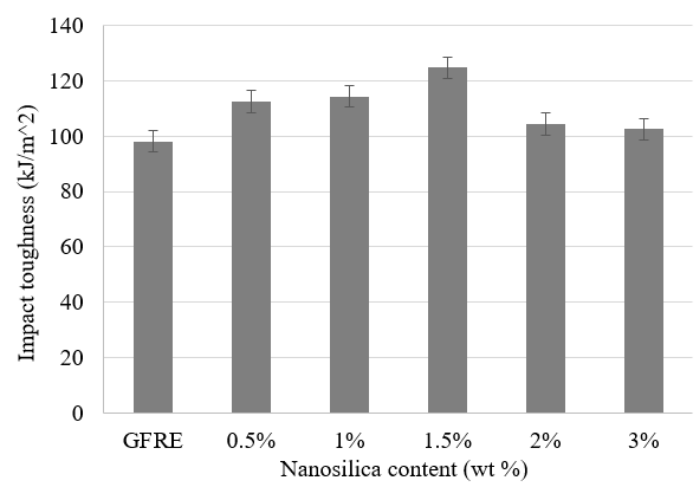

Figure 7. Impact toughness of flatwise-unnotched impacted with respect to nanosilica content.

\section{Conclusions}

In this study, the effects of nanosilica inclusion on the impact behavior of glass/epoxy fiber reinforced composite laminates were investigated by conducting Charpy impact tests. For each nanosilica content, five specimens as notched and unnotched were exposed to edgewise and flatwise impact loading. Impact energy and impact toughness results were obtained and compared to specimens having pure epoxy matrix. 38.02\%, $30.86 \%$ for edgewise-notched specimens and $32.83 \%, 27.1 \%$ for flatwise-unnotched specimens increase in impact energy and toughness were obtained from the test results. The best improvements were achieved on the addition of $1.5 \mathrm{wt} \%$ nanosilica inclusion for both situations. Also, all addition of nanosilica weight percentages gave the improvements compared to pure ones. 
As seen in the results, nanosilica addition in the matrix the crucial effects on the impact behavior of the fiber reinforced composite laminates even the usage of very small amounts. It can be recommended in the engineering applications.

\section{Acknowledgements(11 PT) (Optional)}

Some glass fiber data was benefited from a M.Sc. thesis studies of AtbanRafeaAbdo supported by the Gaziantep University Scientific Research Projects (B.A.P) under grant number MF.YLT.16.14.

\section{References(11 PT)}

[1] M. Jawaid, A. el Kacem Qaiss, R. Bouhfid, "Nanoclay Reinforced Polymer Composites: Natural Fibre/Nanoclay Hybrid Composites," Springer, 2016.

[2] A. Moisala, Q. Li, I. A. Kinloch, A. H. Windle, "Thermal and electrical conductivity of single- and multiwalled carbon nanotube-epoxy composites," Composite science and technology, 66(10), pp. 1285-1288, 2006.

[3] R. Goyal, M. Sharma, U. K. Amberiya, "Innovative nano composite materials and applications in automobiles," International Journal of Engineering Research and Technology, 3(1), 2014.

[4] K. L. Kuzmin, I. A. Timoshkin, S. I. Gutnikov, E. S. Zhukovskaya, Y. V. Lipatov, B. I. Lazoryak, "Effect of silane/nano-silica on the mechanical properties of basalt fiber reinforced epoxy composites," Composite Interfaces, 24(1), pp. 13-34, 2017.

[5] C. Y. Huang \& J. L. Tsai, "Characterizing vibration damping response of composite laminates containing silica nanoparticles and rubber particles," Journal of Composite Materials, 49(5), pp. 545-557, 2015.

[6] Y. Zeng, H. Y. Liu, Y. W. Mai, X. S. Du, "Improving interlaminar fracture toughness of carbon fibre/epoxy laminates by incorporation of nano-particles," Composite Part B: Engineering, 43(1), pp. 9094, 2012.

[7] C. M. Manjunatha, A. C. Taylor, A. J. Kinloch, S. Sprenger, "The tensile and fatigue behaviour of a silica nanoparticle-modified glass fibre reinforced epoxy composite," Composite Science and Technology, 70(1), pp. 193-196, 2010.

[8] T. J. Kang, K. H. Hong, M. R. Yoo, "Preparation and properties of fumed silica/Kevlar composite fabrics for application of stab resistant material," Fibers and Polymers, 11(5), pp. 719-724, 2010.

[9] P. Rosso, L. Ye, S. Sprenger, "A toughened epoxy resin by silica nanoparticle reinforcement," Journal of Applied Polymer Science, 100(3), pp. 1849-1855, 2006.

[10] M. Zamanian, M. Mortezaei, B. Salehnia, J. E. Jam, "Fracture toughness of epoxy polymer modified with nanosilica particles: Particle size effect,” Engineering Fracture Mechanics, 97, pp. 193-206, 2013.

[11] J. K. Pandey, K. R. Reddy, A. K. Mohanty, M. Misra, "Handbook of Polymer nanocomposites. Processing, Performance and Application Volume A: Layered Silicates," Germany: Springer-Verlag Berlin Heidelberg, 2014.

[12] ISO, EN. "179: 72." Plastics -- Determination of Charpy impact properties -- Part 1: Non-instrumented impact test. 